\title{
Broadband tonpilz underwater acoustic transducers based on multimode optimization
}

\author{
Yao, Qingshan; Jensen, Leif Bjørnø
}

Published in:

I E E E Transactions on Ultrasonics, Ferroelectrics and Frequency Control

Link to article, DOI:

$10.1109 / 58.655631$

Publication date:

1997

Document Version

Publisher's PDF, also known as Version of record

Link back to DTU Orbit

Citation (APA):

Yao, Q., \& Jensen, L. B. (1997). Broadband tonpilz underwater acoustic transducers based on multimode optimization. I E E E Transactions on Ultrasonics, Ferroelectrics and Frequency Control, 44(5), 1060-1066. https://doi.org/10.1109/58.655631

\section{General rights}

Copyright and moral rights for the publications made accessible in the public portal are retained by the authors and/or other copyright owners and it is a condition of accessing publications that users recognise and abide by the legal requirements associated with these rights.

- Users may download and print one copy of any publication from the public portal for the purpose of private study or research.

- You may not further distribute the material or use it for any profit-making activity or commercial gain

- You may freely distribute the URL identifying the publication in the public portal 


\title{
Broadband Tonpilz Underwater Acoustic Transducers Based on Multimode Optimization
}

\author{
Qingshan Yao and Leif Bjørnø, Fellow, IEEE
}

\begin{abstract}
Head flapping has often been considered to be deleterious for obtaining a tonpilz transducer with broadband, high power performance. In the present work, broadband, high power tonpilz transducers have been designed using the finite element (FE) method. Optimized vibrational modes including the flapping mode of the head are effectively used to achieve the broadband performance. The behavior of the transducer in its longitudinal piston mode and in its flapping mode is analyzed for in-air and in-water situations. For the $37.8 \%$ bandwidth of the center frequency from 28.5 to $41.8 \mathrm{KHz}$, the amplitude variation of the transmitting voltage response (TVR) does not exceed $\pm 2 \mathrm{~dB}$ and a maximum TVR of $146.8 \mathrm{~dB}$ (ref. $1 \mu \mathrm{Pa}$ /volt at 1 meter) is obtained. Reasonable agreement between the experimental results and the numerical results is achieved. A maximum sound pressure level of $214.8 \mathrm{~dB}$ can be expected. Further numerical calculation indicates that there is potential for increasing the bandwidth by varying other parameters in the design.
\end{abstract}

\section{INTRODUCTION}

$\mathrm{T}$ HE TONPILZ TRANSDUCER is one of the most popular types of sonar transducer, and its low cost, simplicity, and good performance are well known. The typical configuration of a tonpilz transducer is shown in Fig. 1. The conventional tonpilz transducer, as a longitudinal vibrator, has a limited bandwidth. Due to the imperative needs for high accuracy and high resolution sonar systems, broadband tonpilz transducers are required. The bandwidth of the tonpilz transducer may be improved to a limited extent by reducing the thickness or increasing the front diameter of the cone head. Both of these approaches may lead to the appearance of flexural resonances of the head. In the past, sophisticated numerical techniques (e.g., FE) were not available. As a consequence, the vibrational and the acoustical behavior of a tonpilz transducer with many modes of vibration, could not be well understood and optimized sufficiently. The presence of the flexural mode of the head, often referred to as head flapping, has been recognized for many years and has usually been considered to have a negative influence on the performance, in particular by reducing the bandwidth and acoustic power output [1]. The recommended design procedure to avoid problems

Manuscript received July 2, 1996; accepted March 17, 1997. This research is funded by the European Union under contract MAS2CT91-0010.

The authors are with the Department of Industrial Acoustics, Technical University of Denmark, DK-2800, Lyngby, Denmark (e-mail: qyao@bk.dk). is to ensure that the flapping resonance frequency is well above the operating frequency, which is normally the resonance frequency of the fundamental piston mode of the transducer [2]. The in-air vibration modes, including the flapping mode of the tonpilz transducer, have been investigated using the FE method by, for example, Hamonic [3] and Decarpigny et al. [4]. An alternative approach, using an equivalent circuit method [5], has been used by Butler et al. [6]. In contrast to the normal view that head flapping is undesirable, the investigation has shown that it is possible to use the flexural motion to a positive effect.

Various methods have been used to achieve broadband design. Two of the successful achievements are the matching layer technique [7]-[9] and the design of multimass tonpilz transducers [1], [10], respectively. The matching layer technique uses one or more layers on the front face of the radiating head, where the characteristic impedances of the different layers are optimized [11]. A transducer which has a $-6 \mathrm{~dB}$ bandwidth of $65.2 \%$ has been reported [8]. The transducer comprises three layers of alumina-epoxy composites in different percentages. The multi-mass design seeks to transform the normal tonpilz configuration of spring (piezoceramic) and double-masses (head and tail) into one with three masses and two springs [1], [10]. The ceramic stack of the transducer is divided into two parts, constituting two springs, and an additional metal mass is assembled between the two ceramic springs. The three masses and two springs change the transducer into a tworesonance system leading to a camel-shaped transmitting voltage response (TVR) with a broadband performance. A $-6 \mathrm{~dB}$ bandwidth of about $86 \%$ has been found for this type of design [1]. Most of the attempts at obtaining broadband tonpilz transducers, including the multilayered and the multimass approaches, lead to complications in manufacturing and assembling of the transducers.

In this paper, the possibilities of achieving a broadband tonpilz transducer using different vibrational modes, while maintaining the simple conventional configuration, is in vestigated. The basic modes used are the piston mode of the whole transducer and the flapping mode of the head, respectively. In-air analysis is performed to understand the free vibrational behavior at different modes. In-water analysis is mainly concentrated on obtaining the broadband TVR by optimizing the transducer structure. The phenomenon of in-air mode shape change between the flapping and longitudinal piston modes is found. The waterloaded vibrational displacements of the transducer and the pressure TVR provide comprehensive understanding of the behavior of the multimode broadband tonpilz transducer. 


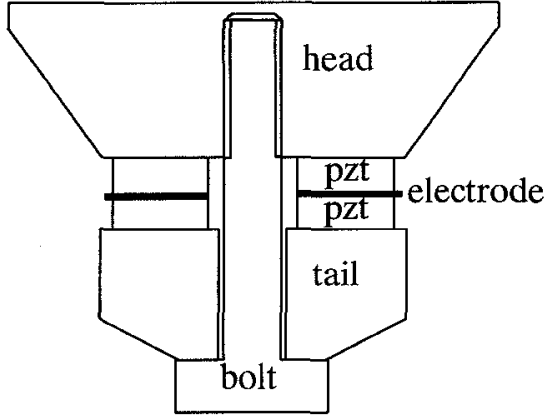

Fig. 1. Schematic diagram of a tonpilz transducer.

\section{Design Description}

The multimode tonpilz transducer studied has the simple conventional configuration shown in Fig. 1. The cone radiation head is made of light aluminum alloy while the tail mass is made of brass. Two Navy type I (PZT4) piezoceramic rings are used for the active material. The steel bias bolt compresses the two piezoceramic rings and ensures that stresses in the ceramic stack are always compressive. In earlier designs, the cone head was designed to provide a larger radiating area, improved radiation impedance, and better impedance matching, and so lead to a relatively higher bandwidth and larger acoustic power. In the multimode broadband design, the head is the most critical part. The design procedures are as follows. First, the ordinary one-dimensional transmission line method can be used to obtain the primary geometrical dimensions of the transducer (e.g., the thickness of the tail and the head). Second, the in-air FE model analysis may be used to find the fundamental piston mode and the fundamental flapping mode, respectively. The angle of the taper of the cone is selected on the criterion that the resonance frequencies of the flapping and piston modes should be neither too close nor too separated. Third, the in-water analysis may be used to optimize the geometrical dimensions to some extent with the aim of increasing the bandwidth of the TVR. The design procedures are the same when other modes are used to extend the bandwidth (e.g., the mode related to the prestress bolt, where the variable parameter is the bolt diameter).

\section{Finite Element Analysis}

A commercial FE package (i.e., ANSYS) is implemented for the calculation. The transducer is modeled as a continuous structure. The electrode, which is $0.25 \mathrm{~mm}$ thick, is also modeled. Due to the large prestress, the glue layers are very thin compared to the wavelength at the working frequencies studied. Thus, the glue was not taken into account. 2-D axisymmetric triangle and quadrilateral elements are used jointly in the FE model. For in-water harmonic analysis, the fluid-structure interaction and farfield acoustic absorption capabilities of the FE code are exploited, respectively [12].

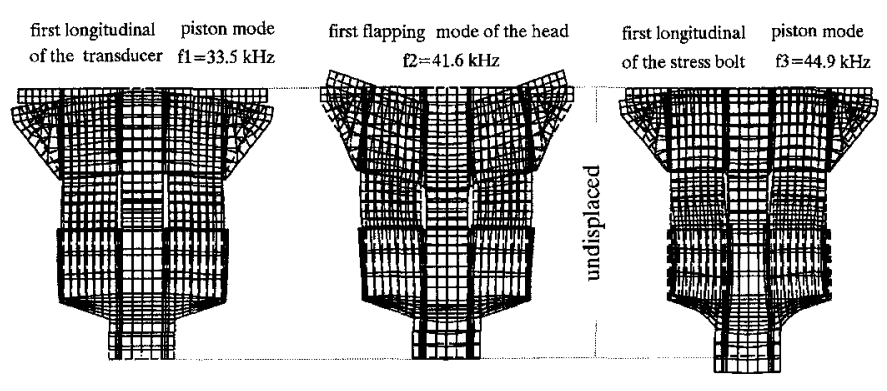

Fig. 2. The in-air deformed shapes of the first three modes.

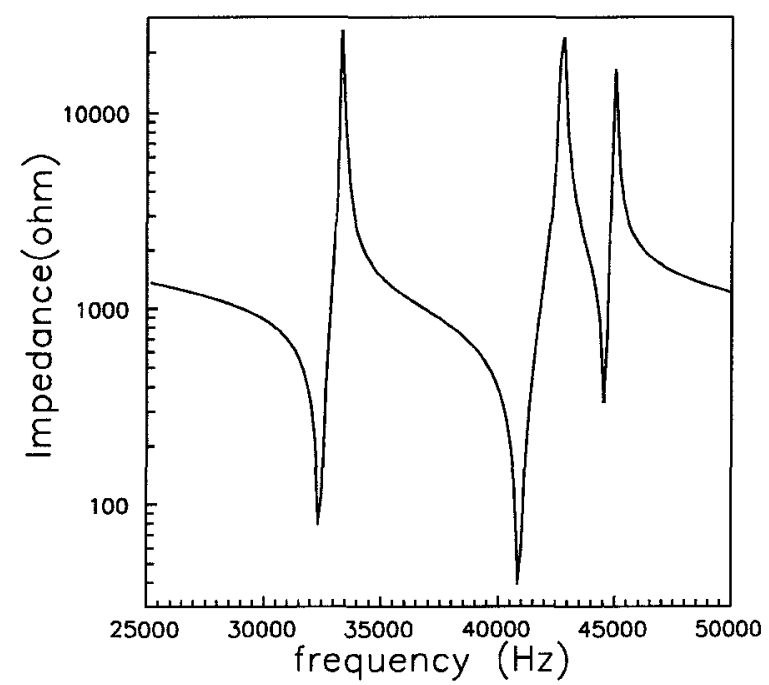

Fig. 3. In-air impedance of the tonpilz transducer.

\section{A. In-air Analysis}

The FE modal analysis is implemented to optimize the geometrical configuration and select the proper materials used for different components of the transducer. The design goals in this primary step are to find the vibrational mode shapes and to locate the proper resonance frequencies of different vibrational modes in the required frequency band. For a typical multifrequency tonpilz transducer design, the deformed shapes of the transducer at the first three modes are shown in Fig. 2. The diameter of the front surface of the head is $60 \mathrm{~mm}$ for this transducer compared to a ceramic diameter of $40 \mathrm{~mm}$. The first two modes are mainly related to the fundamental piston mode of the tonpilz and the fundamental flapping mode of the head, while the third mode is mainly caused by the longitudinal vibration of the prestress bolt. This can be distinguished more easily by looking at the large displacements at the bottom of the prestress bolt in the third picture of Fig. 2 . The resonance frequencies of the three modes are 33.5, 41.6 , and $44.9 \mathrm{KHz}$, respectively. The predicted in-air electrical impedance of the transducer is also calculated and plotted in Fig. 3. The three valley points in the impedance plot correspond to the first three modes as shown in Fig. 2.

The modal analysis also shows that the resonance frequencies of the first and the second modes may be lowered by increasing the diameter of the front face of the 
head. The dependencies of the resonance frequencies on the geometrical sizes is used for optimizing the resonance frequencies at different modes to obtain a wideband TVR. A tonpilz transducer having resonance frequencies of different modes that are too close may not exploit the bandwidth capability of the multimode transducer, while one that has very separated resonances could result in a serious reduction in the TVR at intermediate frequencies. In the multimode design, mode coupling between the longitudinal piston mode and the flapping mode produces somewhat complicated in-air and in-water mode shapes. The modes superimpose together and neither a pure piston mode nor a pure flapping mode exists in the frequency regime studied. A phenomenon, namely the change of in-air dominant mode shape, has been found. When the diameter of the front and the back surface of the head are not too different (e.g., $56 \mathrm{~mm}$ and $40 \mathrm{~mm}$, respectively) the first mode is longitudinal piston dominant while the second mode is flapping dominant. When the diameter of the front face increases above a certain value, the property of the first mode changes from longitudinal piston dominated to flapping dominated. This can be demonstrated by the vector displacements on the front and the back of the transducer in Figs. 4 and 5. In Figs. 4(a) and 5(b), the opposite directions of the displacements at two ends in the central part of the transducer represent the $\lambda / 2$ piston mode. In Figs. 4(b) and $5(\mathrm{a})$, the nodes in the central part of the transducer vibrate in the same direction forming in-phase body displacements, while the nodes in the edge part of the head vibrate in the opposite direction representing a typical flapping property of the head. The critical value of the diameter of the front surface of the head, at which the change of the dominant mode happens is about $64 \mathrm{~mm}$ in air.

\section{B. In-water Analysis}

In the FE analysis, the coupling between the transducer and water can be taken into account by implementing fluid-structure-interaction elements at the fluid-structure interface. By performing the in-water harmonic analysis, the in-water electrical impedance and TVR of the transducer can be predicted. The main purpose of optimizing the design is to obtain a broadband, low-ripple TVR of the transducer. The TVRs of the tonpilz transducers with different diameters of the front face of the head are calculated and shown in Fig. 6 . The double resonance peaks form a camel-shaped TVR, allowing multimode broadband tonpilz transducers to be obtained.

The ripple in the bandwidth can be controlled by varying the diameter of the front face of the head. It may be noticed in Fig. 6 that the resonance frequency of the first mode drops more significantly than that of the second mode while the diameter increases. As shown in Fig. 6, the resonance frequencies of the first mode are 33.7, 31.0, and $27.7 \mathrm{KHz}$ for the diameter of 56,60 , and $64 \mathrm{~mm}$, respectively. By using an analytical method (i.e., equivalent circuit method), the resonance frequencies of fundamental piston mode are calculated to be $33.6,32.2$, and $30.9 \mathrm{KHz}$,

$$
\text { In-air analysis } \quad \mathrm{Dh}=56 \mathrm{~mm}
$$

first mode: $35.3 \mathrm{kHz}$ longitudinal piston mode dominant

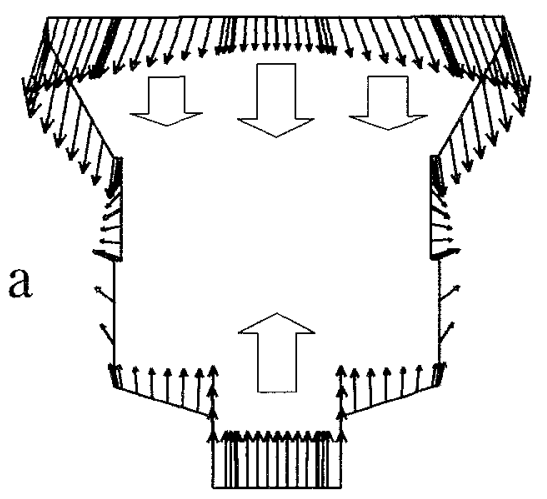

second mode: $42.7 \mathrm{kHz}$

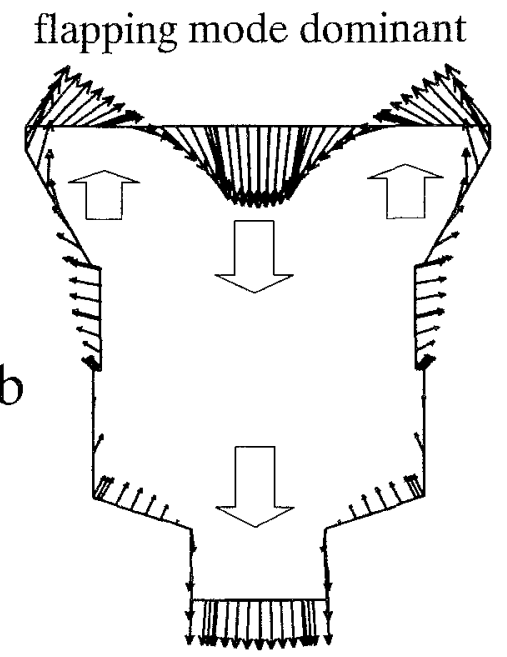

Fig. 4. In-air surface displacements at the first two modes for a small value of the front diameter.

accordingly. It can be proven, especially by the results from the equivalent circuit method, that the reduced resonance frequency of the first mode mainly results from the larger head mass and the water load mass of the head for increasing the head diameter. Due to the interaction between the transducer structure and the water medium, the vibrational behavior of the transducer becomes more complicated. The head flapping appears at much lower frequency than in air. It is more difficult to judge the vibrational characteristics by visualizing the deformed shapes. Therefore, another method is used to assess the vibrational behavior by calculating the surface displacements of the transducer. All displacements receive contributions from all the existing modes at a specified frequency. Typical points, or nodes, used for monitoring the modes are the central point and the edge point of the front surface of the head as well as the central point of the bolt on the 


$$
\text { In-air analysis } \quad \mathrm{Dh}=68 \mathrm{~mm}
$$

first mode: $28.57 \mathrm{kHz}$

flapping mode dominant

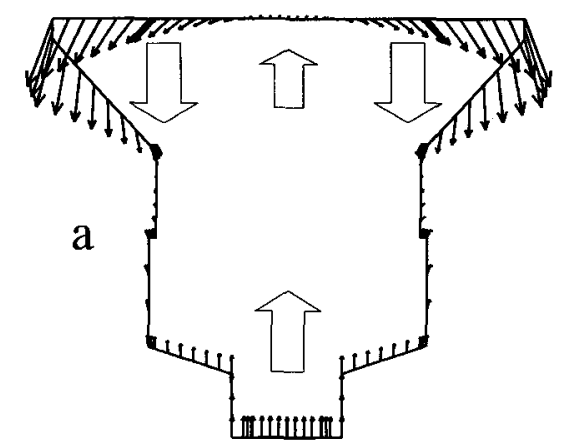

second mode: $39.2 \mathrm{kHz}$

longitudinal piston mode dominant

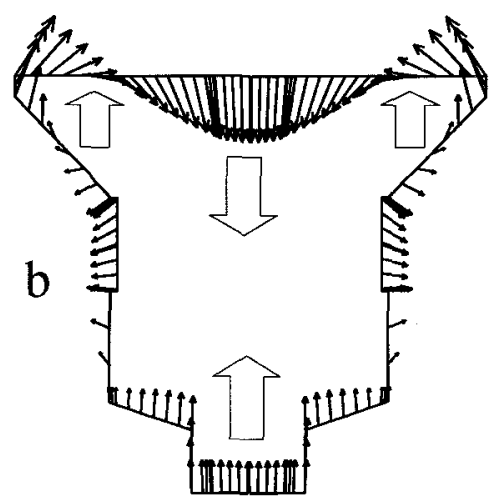

Fig. 5. In-air surface displacements at the first two modes for a large value of the front diameter.

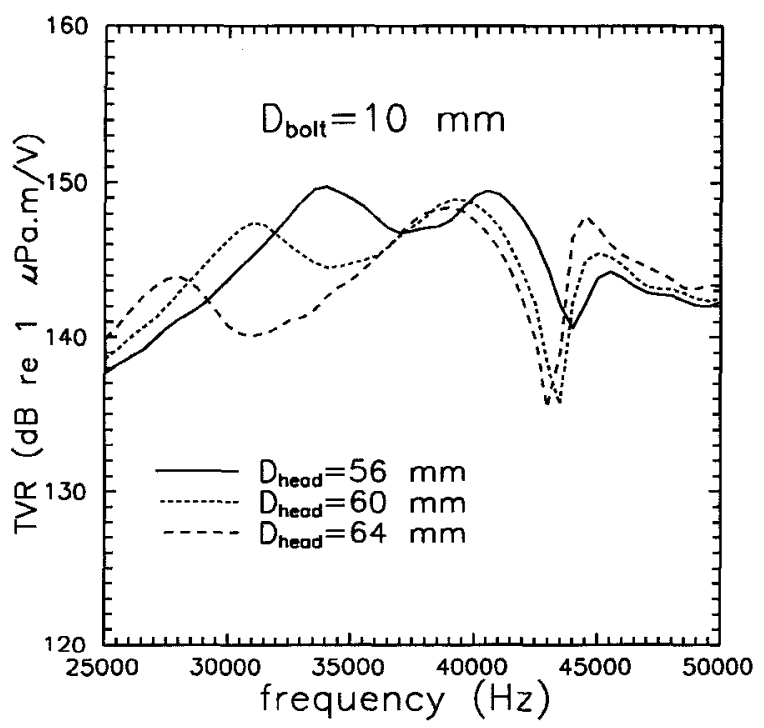

Fig. 6. Transmitting voltage response (TVR) of the tonpilz transducers with different front diameters of the head.

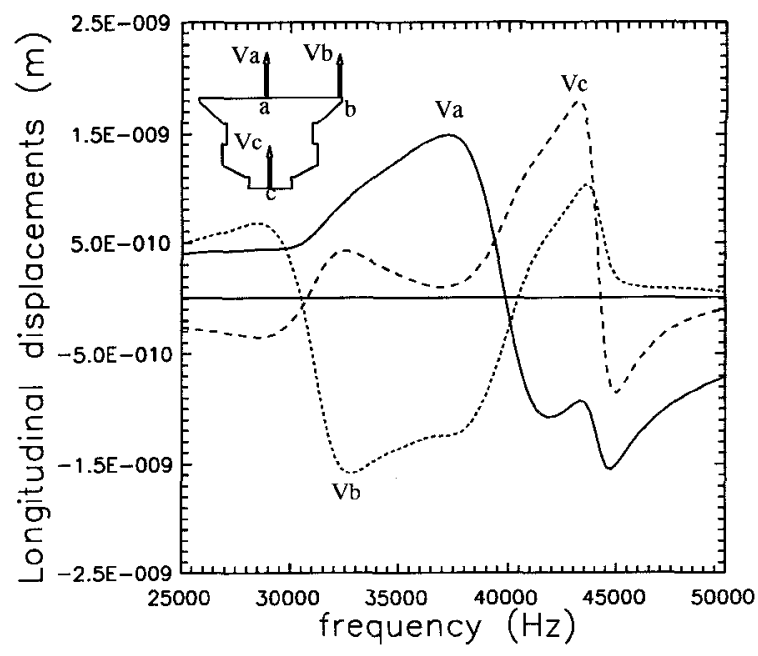

Fig. 7. In-water longitudinal displacements of three selected nodes of the transducer.

back of the transducer, respectively. The displacements in the longitudinal direction as functions of frequency for a transducer with a front diameter of $60 \mathrm{~mm}$ are depicted in Fig. 7 .

In the low-frequency region, $f<30 \mathrm{KHz}, V_{a}$ and $V_{b}$ have the same directions representing the simple pistontype vibrational motion. As the frequency increases from $30.5 \mathrm{KHz}$, the flapping of the head appears and the mode shapes become complicated. The maximum negative value of $V_{b}$ around $32 \mathrm{KHz}$ indicates the significant influence of the flapping mode. Around $45 \mathrm{KHz}$, the maximum value of $V_{c}$ indicates the bolt relevant mode. One may find by comparing the TVR in Fig. 6 and the displacements plots in Fig. 7 that the frequencies of the peaks in the TVR do not coincide with the frequencies at which $V_{a}$ and $V_{b}$ reach their peak amplitudes. This is due to the fact that the pressure field is formed by a combination of the various contributions from the surface of the transducer. Therefore, the properties of the integrated pressure could be different from the individual vibrational properties of the transducer structure.

The in-air longitudinal displacements around the resonance frequency of the first mode as a function of frequency are shown in Fig. 8. It can be seen from Fig. 8 that $V_{a}$ and $V_{b}$ have the same direction corresponding to the in-phase piston motion at the first mode. Note that in Fig. $7 V_{a}$ and $V_{b}$ change to out-of-phase flapping motion while the transducer is water-loaded. Therefore, the head flapping appears at lower frequency than it appears in air due to the water load. Under these circumstances, the inair modal analysis does not provide a reliable guide to its in-water vibrational behavior.

\section{EXPERIMENTAL RESULTS}

A tonpilz transducer prototype has been built on the basis of the optimized design aiming at high power broadband performance. The diameter of the head front is 


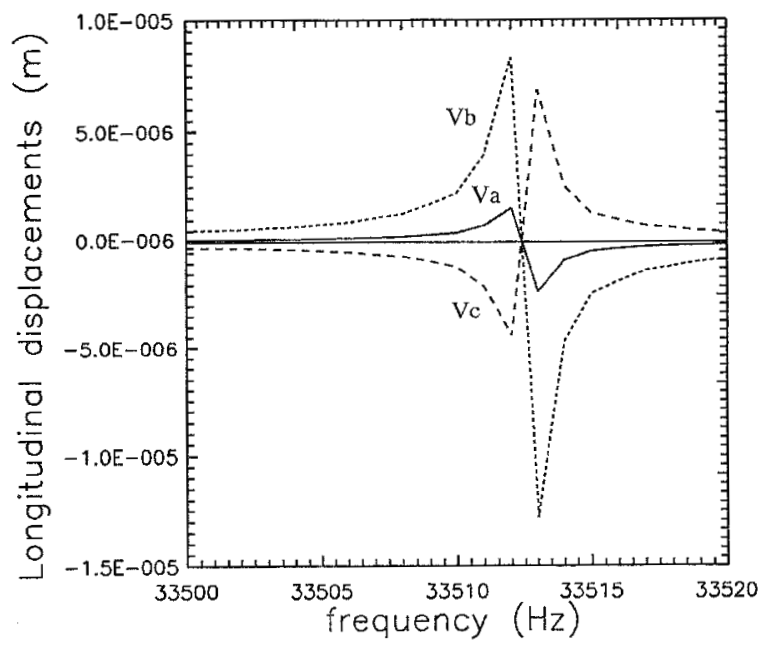

Fig. 8. In-air longitudinal displacements of the three selected nodes of the transducer around the first mode.

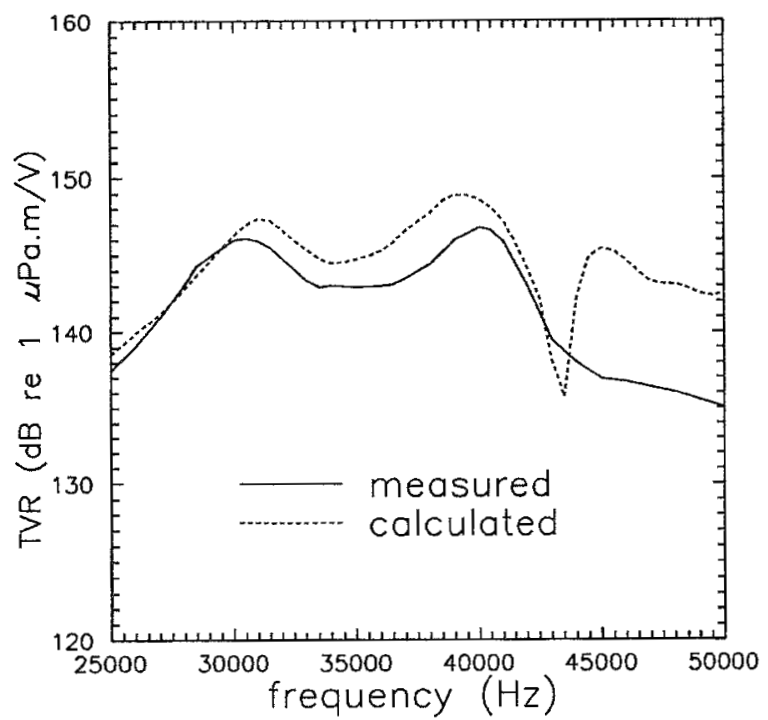

Fig. 9. Measured and calculated transmitting voltage response.

$60 \mathrm{~mm}$. The measured and calculated TVR results are shown in Fig. 9. The measured TVR value is somewhat lower than the numerical result in the frequency region between 25 and $43 \mathrm{KHz}$. Several possible factors (e.g., the mechanical losses and the difference between the real material data and the data used in the calculations) could result in the deviation. According to the measured TVR result shown in Fig. 9, for the $37.8 \%$ bandwidth of the center frequency from 28.5 to $41.8 \mathrm{KHz}$, the amplitude variation of the TVR does not exceed $\pm 2 \mathrm{~dB}$. According to the practical applied voltage limitation of $4000 \mathrm{volt} / \mathrm{cm}$ for Navy type I ceramics, the maximum sound pressure level is $214.8 \mathrm{~dB}$ (ref. $1 \mu \mathrm{Pa}$ at 1 meter). The calculated and measured in-water electrical resistance and reactance are plotted in Fig. 10. The measured and calculated beam patterns at $30.4 \mathrm{KHz}$ are shown in Fig. 11.

It may be noticed in Figs. 9 and 10 that the third mode which is related to the piston mode of the prestress bolt does not appear in the measured TVR and impedance re-

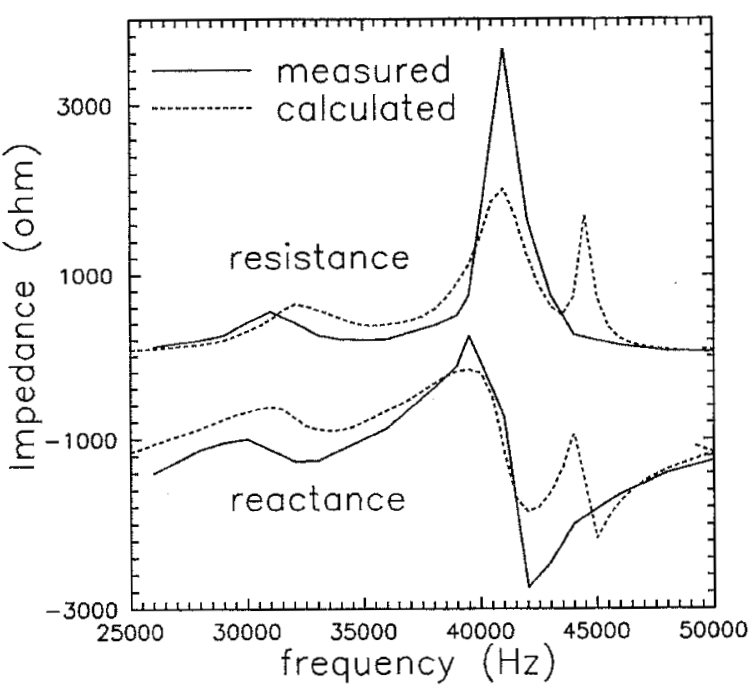

Fig. 10. Measured and calculated impedance.

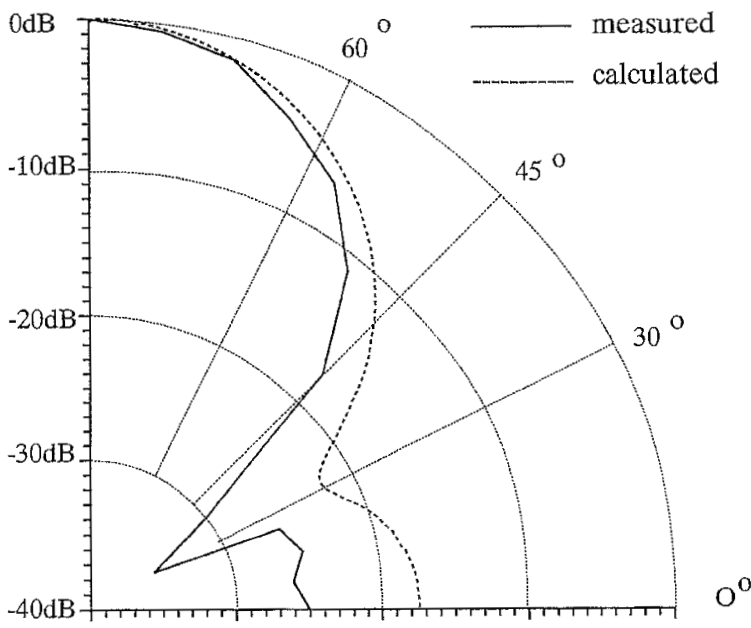

Fig. 11. Measured and calculated beam patterns at $30.4 \mathrm{KHz}$.

sults. A possible explanation for this lies in the difficulty of modelling the screw joints at the head and tail of the bolt. The FE model is based on an assumption of an ideal connection, and this is not accurate enough to predict the results in the frequency regime in which the influence of the prestress bolt connection is significant. More research related to the influence of the screw joint is necessary.

\section{Further Optimization}

More calculations show that the bandwidth may be extended further using the vibrational mode of the optimized prestress bolt. Predicted TVRs of the tonpilz transducer with different diameters of the boit are shown in Fig. 12. It can be seen that the resonance frequency of the third peak in the TVRs decreases as the bolt diameter increases. However, the modal analysis shows that the in-air resonance frequency of the third mode does not have this dependency. The mechanism of this dependence between the third peak resonance frequency in TVR and the bolt di- 


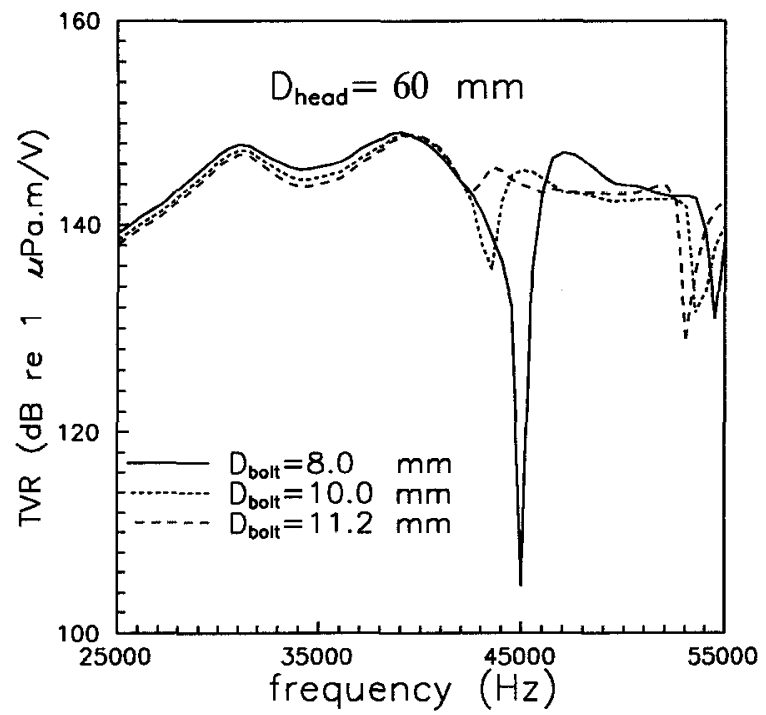

Fig. 12. Transmitting voltage responses of tonpilz transducers with different diameters of the prestress bolt.

ameter is presently under investigation. At the same time, the amplitude in the trough of the TVRs incrcases leading to an improved bandwidth. For a prestress bolt with a diameter of $11.8 \mathrm{~mm}$, the bandwidth is extended to $60 \%$ spanning the range 28 to $54 \mathrm{KHz}$, if the allowed TVR ripple is increased to $6 \mathrm{~dB}$.

The assumption of an ideal connection of the bolt-head and bolt-tail joint connections in the FE model, instead of the actual screwed connection, could lead to a significant deviation between numerical results and experimental results near the bolt-dependent resonance frequencies. It could be helpful to minimize the deviation using a smallpitch screw combined with glued assembly.

\section{Conclusions}

A broadband, high-power tonpilz transducer can be obtained using multimode operation including the flapping mode of the head. By using the fundamental longitudinal mode and the flapping mode together, the amplitude variation of the TVR does not exceed $\pm 2 \mathrm{~dB}$ from 28.5 to $41.8 \mathrm{KHz}$. A maximum sound pressure level of $214.8 \mathrm{~dB}$ (ref. $1 \mu \mathrm{Pa}$ at 1 meter) can be expected according to the measured maximum TVR of $146.8 \mathrm{~dB}$ (ref. $1 \mu \mathrm{Pa} /$ volt at 1 meter). The vibrational mode in relation to the prestress bolt of the tonpilz transducer is another potential mode which can be used to improve the bandwidth further. In conjunction with the piston mode and the flapping mode, $\mathrm{a}-6 \mathrm{~dB}$ bandwidth of $60 \%$ is predicted.

The flapping mode of the cone head plays an important role in the multimode broadband design. For the transducer studied, the in-air modal analysis shows that the first mode shape is longitudinal piston dominant and the second is flapping dominant. But in water, the water load leads to the earlier appearance of the head flapping. This head flapping superposes to the piston mode leading to the deformed shape of flapping even at the resonance frequency of the piston mode. Due to the sensitive effect of the head mass and the load mass on the piston mode, the first resonance frequency in the TVR strongly depends on the front diameter of the head.

\section{REFERENCES}

[1] S. C. Thompson and M. P. Johnson, "Performance and recent developments with doubly resonant wideband transducers," Proc. 3rd Int. Workshop Transducers Sonics Ultrason., Orlando, FL, M. D. McCollum, B. F. Hamonic, and O. B. Wilson, Eds., Bath, U.K., 1992, pp. 239-249.

[2] D. Stansfield, Ed., Underwater Electroacoustic Transducers. Bath University Press, 1991, pp. 215-217.

[3] B. Hamonic, "Application of the finite element melhod to the design of power piezoelectric sonar transducers," Proc. Transducers Sonics Ultrason., Lille, France, B. Hamonic and J. N. Decarpigny, Eds., 1987, pp. 143-159.

[4] J. N. Decarpigny, J. C. Debus, B. Tocquet, and D. Boucher, "In-air analysis of piezoelectric tonpilz transducers in a wide frequency band using a mixed finite element-plane wave method," J. Acoust. Soc. Amer., vol. 78, no. 5, pp. 1499-1507, 1985.

[5] W. P. Mason, Ed., Electromechanical Transducers and Wave Filters. Princeton, NJ: Van Nostrand, 1948.

[6] J. L. Butler, J. R. Cipolla and W. D. Brown, "Radiating head flexure and its effect on transducer performance," J. Acoust. Soc. Amer., vol. 70, no. 2, pp. 500-503, 1981.

[7] G. Kossoff, "The effects of backing and matching on the performance of piezoelectric ceramic transducers," IEEE Trans. Sonics Ultrason., vol. SU-13, no. 1, pp. 20-30, 1966.

[8] T. Inoue, T. Nada, T. Tsuchiya, T. Nakanishi, T. Miyama, S. Takahashi, and M. Konno, "Tonpilz piezoelectric transducers with acoustic matching plates for underwater colour image transmission," Acoust. Imaging, vol. 17, pp. 597-607, 1989.

[9] B. V. Smith, R. L. Mansfield, D. T. I. Francis, and J. R. Dunn, "The design of a $100-\mathrm{KHz}$ wideband sonar transducer," Proc. Transducers Sonics Ultrason., Orlando, FL, M. D. McCollum, B. F. Hamonic, and O. B. Wilson, Eds., pp. 231-237, 1992.

[10] A. G. Flliott, "The design of a high power broadband noise source," Proc. Inst. Acoustics, London, U.K., vol. 12, no. 4, p. $126,1990$.

[11] M. V. Crombruggo and W. Thompson, Jr., "Optimization of the transmitting characteristics of a Tonpilz-type transducer by proper choice of impedance matching layers," J. Acoust. Soc. Amer., vol. 77, no. 2, p. $747,1985$.

[12] ANSYS User's Manual for Revision 5.0, Vol. I, Vol. IV. Houston: Swanson Analysis Systems, 1993.

[13] D. W. Hawkins and P. T. Gough, "Multiresonance design of a tonpilz transducer using finite element method," IEEE Trans. Ultrason., Ferroelect., Freq. Contr., vol. 43, pp. 782-790, Sept. 1996.

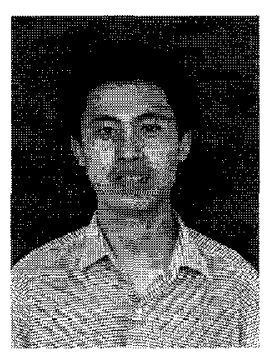

Qingshan Yao was born in 1962 in Liaoning, China. He received the B.S. and M.S. degrees in underwater acoustic engineering from the Harbin Engineering University, Harbin, China, in 1984 and 1987, respectively. from 1987 to 1992 , he was engaged in the research and teaching of underwater acoustic transducers and their array at the same university. Currently he has been working toward the Ph.D. degree, at the Department of Industrial Acoustics, Technical University of Denmark. His research interests include the design of transducers and array analysis. 


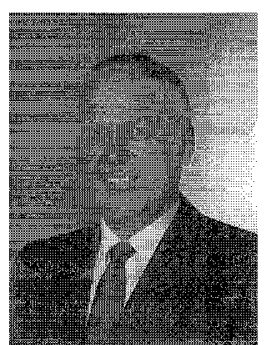

Leif Bjørnø (M'78-M'89-F'92) was born on March 30, 1937, in Svendborg, Denmark. He received the M.Sc. and the Ph.D. degrees in fluid mechanics and physical acoustics from the Technical University of Denmark in 1962 and 1967, respectively. In 1971 he received the D.I.C. degree in physical acoustics from the Imperial College of Science and Technology, London. Currently, he is Professor of Industrial Acoustics and Head of the Industrial Acoustics Department at the Technical University of Denmark. He has been a Visiting

Professor to Imperial College of Science and Technology, UK; University of Cape Town, South Africa; University of Texas at Austin University of Madrid, Spain; and Academia Sinica, Beijing, China.

Dr. Bjørnø is member of the Editorial Board for the international journals: ACTA ACUSTICA, ACUSTICA, J. Acoust. Soc. Japan, and Russian Physics-Acoustics Journal. From 1973 to 1994 he was editor for the international journal Ultrasonics. He has authored and co-authored nearly 300 papers in international journals, books, and conference proceedings. He is author and co-author of eight books.
His research interest covers machine noise and vibration, underwater acoustics, nonlinear acoustics, high-power ultrasonics, and sensors and sensory systems. Dr. Bjørn $\varnothing$ has been chairman and member of several international bodies in NATO and in the European Union. As Chairman and member of Board of Directors for industrial companies in Denmark and abroad, Dr. Bjørnø has a broad contact surface to industry. He is National Delegate to the European Union programme for Marine Science and Technology (MAST); National Delegate to the EUROMAR/EUREKA Programme; National Delegate to the Scientific Committee of National Representatives (SCNR) for SACLANT Undersea Research Centre, La Spezia, Italy. He is Knight of the Order of Dannebrog; Professor Honoris Causa at Harbin University of Engineering. China; Member of the Danish Academy of Technical Sciences; Member of the New York Academy of Sciences; a Fellow of the IEEE; a Fellow of the Institute of Acoustics, UK; a Fellow of the Southern African Acoustics Institute; a Fellow of the Acoustical Society of America; an Honorary Member of the Spanish Acoustical Institute; a Corresponding Member of the Institute of Noise Control Engineers, United States; a Member of Sigma Xi; a Member of the Society of Exploration Geophycisists; a Member of the Acoustical Society of Japan; a Member of the U.S. Naval Institute. He was the Stephens Lecturer 1985, UK. 